\title{
Influence of Trawl Geometry and Vertical Distribution of Fish on Sampling with Bottom Trawl
}

\author{
Arill Engås \\ Institute of Fishery Technology Research \\ P. O. Box 1964, 5011 Nordnes-Bergen, Norway \\ and \\ Olav Rune God $\varnothing$ \\ Institute of Marine Research \\ P. O. Box 1870, 5011 Nordnes-Bergen, Norway
}

\begin{abstract}
Studies were initiated at the Institute of Marine Research, Bergen, in 1984 with the aim of improving the reliability of bottom trawl and acoustic survey results for cod and haddock in the Barents Sea. Spread of the wings and doors and height of the trawl were measured during fishing operations, and acoustic recordings of fish densities were obtained. The observations revealed several aspects of geometry and performance of the gear that could reduce its efficiency for sampling different species and size-groups. The acoustic recordings indicated that fish density has a substantial influence on the correlation between estimates of abundance from trawl catches and from acoustic recordings. Furthermore, a day-night discrepancy of integrated acoustic fish abundance was indicated.
\end{abstract}

\section{Introduction}

The Institute of Marine Research, Bergen, Norway, has carried out combined bottom-trawl and acoustic surveys of cod (Gadus morhua) and haddock (Melanogrammus aeglefinus) stocks in the Barents Sea and the Svalbard areas since 1981 (Fig. 1). The results indicated that trawl catches did not accurately reflect the true age structure of cod in the survey area, with fish less than 4 years old being progressively underrepresented in the catches. In addition, there were large discrepancies between the estimates of stock size from the results of the two types of surveys (Hylen and Nakken, MS 1983; Hylen et al., 1987), with the estimates from trawl surveys being consistently much lower than those based on acoustic data. The trawl surveys also showed that catching efficiency of the gear differed from ship to ship. The various vessels which participated in the surveys used the same standard trawl and rigging but with four different doors.

In 1984, the Institute of Marine Research and the Institute of Fishery Technology Research initiated a cooperative research program to improve the reliability of survey results. The first effort in the program was the measurement of the research trawl's geometry during fishing operations, because the shape and motions of the trawl and the doors and bridles influence the efficiency and selectivity of the gear. Results from a preliminary experiment (Engås and West, 1987) identified gear performance characteristics that might influence the sampling efficiency of the trawl.
In this paper, the results of a later experiment are presented, with particular focus on evaluation of the effects of different designs and sizes of trawl doors on gear geometry. In addition, acoustic investigations were carried out with the aim of isolating the effects of

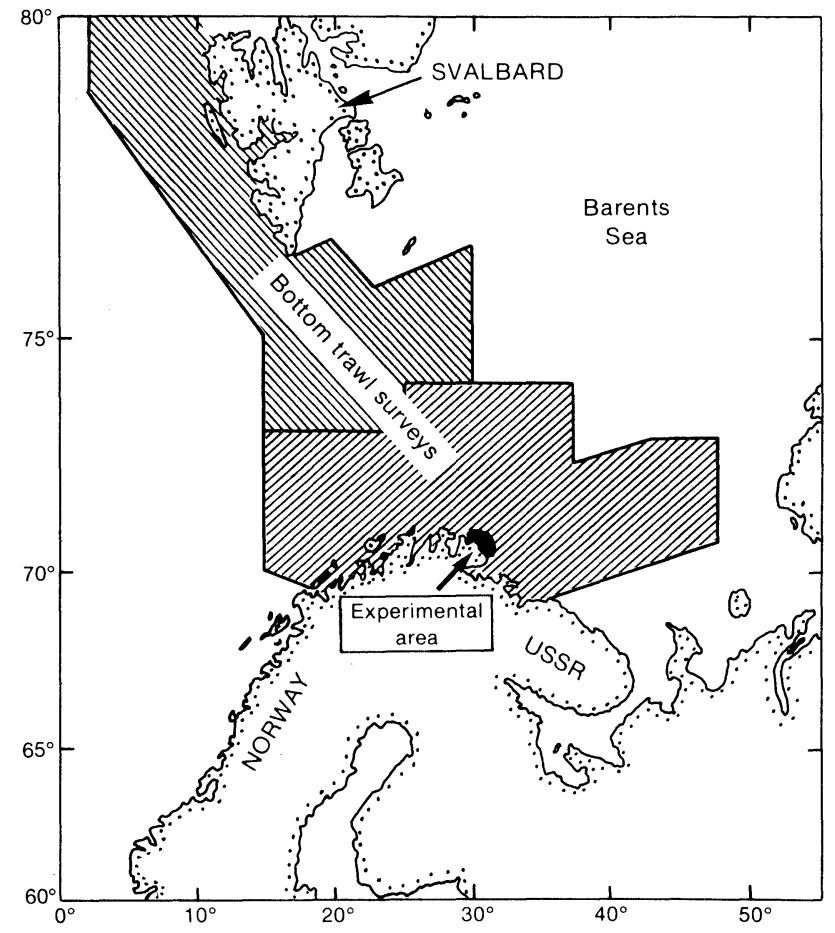

Fig. 1. Areas covered by routine cod and haddock surveys (shaded) and the experimental trawling area in January 1985 (black). 
variation in vertical distribution and density of fish on abundance estimation.

\section{Materials and Methods}

Gear measurements and acoustic investigations were carried out in a limited area of the Barents Sea aboard the research vessel G. O. Sars during 18-26 January 1985 (Fig. 1). The experimental trawl was the standard Norwegian research trawl for sampling bottom fish and shrimp in the Barents Sea and Svalbard areas, namely the Campel 1800 (Fig. 2). The bridle and rigging are also illustrated. Since the surveys in the Barents Sea and Svalbard areas are carried out with bridle lengths of 40 and $80 \mathrm{~m}$ respectively, both lengths were used in the experiments. The three kinds of trawl doors that are normally used on the research vessels were tested: $7.5 \mathrm{~m}^{2}$ Waco-doors $(3.25 \times 2.25 \mathrm{~m}, 1,750$ $\mathrm{kg}), 6.0 \mathrm{~m}^{2}$ Waco-doors $(3.00 \times 2.00 \mathrm{~m}, 1,500 \mathrm{~kg})$, and $6.4 \mathrm{~m}^{2}$ Vee-doors $(3.65 \times 2.02 \mathrm{~m}, 1,750 \mathrm{~kg})$. The fourth type of door $\left(8 \mathrm{~m}^{2}\right.$ Waco) was tested by Engås and West (1987).

The duration of tow was $1 \mathrm{hr}$ at a speed of 1.5 $\mathrm{m} / \mathrm{sec}$ (Doppler-log). The possible effect of currents on gear dimensions was examined by repetition of several tows in the opposite direction. Tows were made during daylight and darkness, with the daytime (including to some extent dawn and dusk) defined as the period from $0730 \mathrm{hr}$ to $1330 \mathrm{hr}$ GMT.

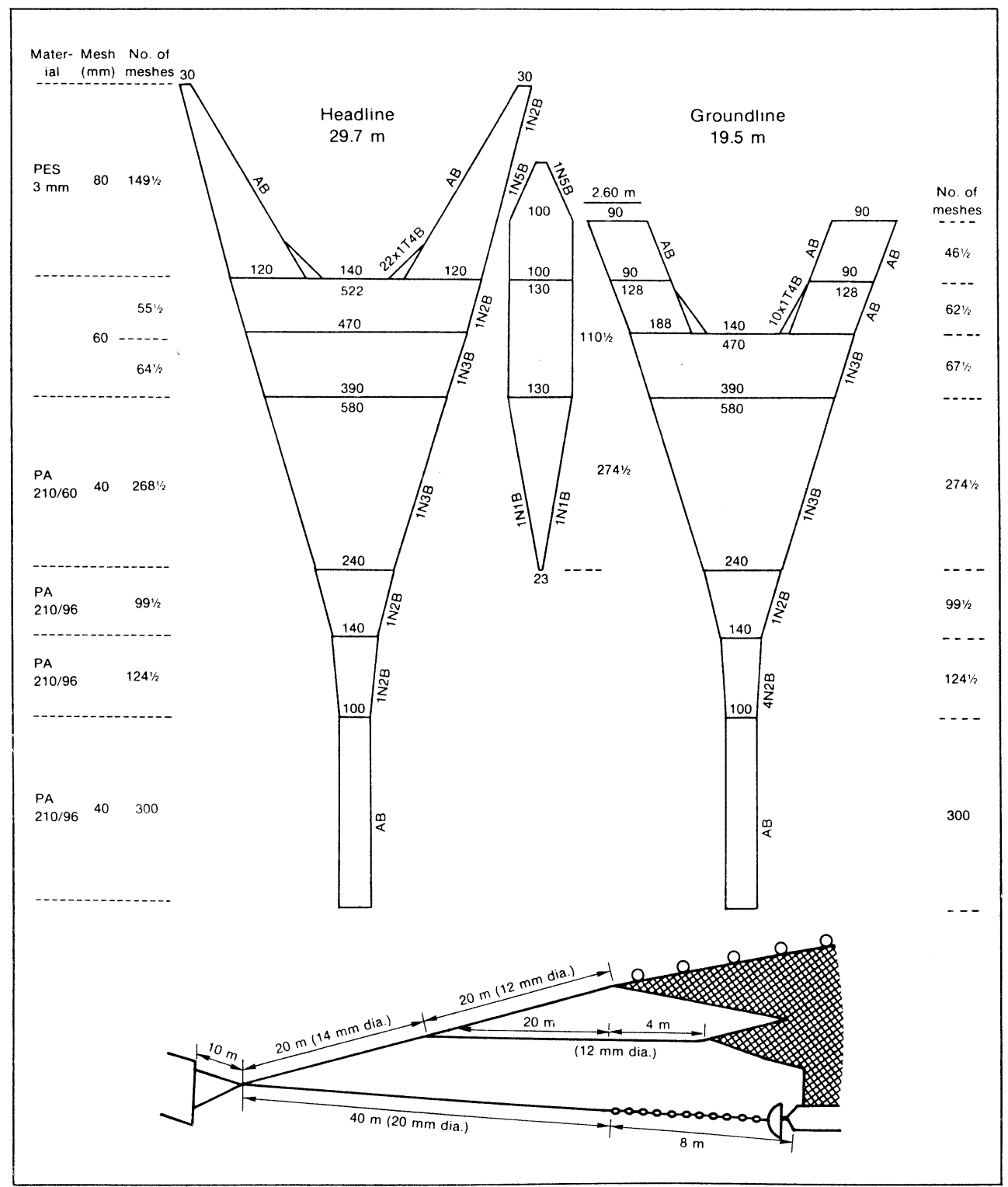

Fig. 2. The standard bottom survey trawl (Campel 1800/96) and rigging specifications. 
The gear dimensions (i.e. headline height, wing spread and distance between the doors) were measured with acoustic trawl instruments (SCANMAR). Wing-spread measurements were obtained by attaching the instruments to the upper bridles approximately $0.25 \mathrm{~m}$ ahead of the wings. For the door-spread measurements, the instruments were attached to the upper backstraps about $2.5 \mathrm{~m}$ behind the doors. All three gear parameters were measured simultaneously during each individual tow.

The acoustic results were obtained with a Simrad EK-400 $38 \mathrm{khz}$ echo-sounder in conjunction with an echo-integrator which was developed by the Institute of Marine Research, Bergen (Blindheim et al., 1982). Standard instrument settings that are normally used during all routine surveys for cod and haddock in the Barents Sea were applied. The only exception was the height of the bottom channel (an integration area of specific thickness following the bottom contour). It was $4 \mathrm{~m}$ during the greater part of the experiment instead of the standard $10 \mathrm{~m}$. In this paper, recordings above the bottom channel are called "pelagic" recordings.

The methods of sampling and estimation of acoustic abundance were described by Dalen and Nakken (MS 1983). The notation "integrator value" is the output value from the integrator, which was judged as cod-haddock registration by its character and by the species composition of the trawl catches. During routine surveys, cod and haddock are considered as one category, and determination of the abundance of the two species is based on their relative abundance in the trawl catches.

\section{Results}

\section{Trawl dimensions}

Measurements were obtained during 28 bottomtrawl tows with three different door types (Table 1 ). Direction of tow did not seem to have any influence on the trawl dimensions.

TABLE 1. Measurements of research trawl height, wing-spread and door-spread aboard the G. O. Sars during experiments with three different doors in January 1985. (Tow b is repeat of tow $a$ in the opposite directon.)

\begin{tabular}{|c|c|c|c|c|c|c|c|}
\hline Door type & $\begin{array}{l}\text { Tow } \\
\text { No. }\end{array}$ & $\begin{array}{l}\text { Depth } \\
(\mathrm{m})\end{array}$ & $\begin{array}{l}\text { Warp } \\
(\mathrm{m})\end{array}$ & $\begin{array}{c}\text { Bridle } \\
(\mathrm{m})\end{array}$ & $\begin{array}{l}\text { Height } \\
(\mathrm{m})\end{array}$ & $\begin{array}{l}\text { Wing-spread } \\
(\mathrm{m})\end{array}$ & $\begin{array}{c}\text { Door-spread } \\
(\mathrm{m})\end{array}$ \\
\hline \multirow{8}{*}{$\begin{array}{l}\text { Waco-doors } \\
\qquad\left(7.5 \mathrm{~m}^{2}\right)\end{array}$} & $1(a)$ & 180 & 450 & 40 & $3.5-3.9$ & $19.0-20.5$ & - \\
\hline & $1(b)$ & $"$ & $"$ & $"$ & $3.5-3.9$ & $19.0-20.5$ & $64-68$ \\
\hline & 2 & 160 & $"$ & $"$ & $3.5-3.9$ & $19.0-20.5$ & $63-66$ \\
\hline & $3(a)$ & " & $"$ & 80 & $3.5-3.9$ & $19.0-20.5$ & $81-88$ \\
\hline & $3(b)$ & 150 & $"$ & $"$ & $3.5-3.9$ & $19.0-20.5$ & $81-89$ \\
\hline & 4 & 150 & 450 & 80 & $3.5-3.9$ & $19.0-20.5$ & $81-89^{a}$ \\
\hline & $5(a)$ & 190 & " & 40 & $3.5-3.9$ & $19.0-20.5$ & $63-67^{a}$ \\
\hline & $5(b)$ & $"$ & $"$ & $"$ & $3.5-3.9$ & $19.0-20.5$ & $64-67^{a}$ \\
\hline Waco-doors & $6(a)$ & 150 & 450 & 40 & $3.9-4.2$ & $17.5-18.5$ & $54-57$ \\
\hline \multirow[t]{13}{*}{$\left(6.0 \mathrm{~m}^{2}\right)$} & $6(b)$ & $"$ & $"$ & $"$ & $3.8-4.2$ & $17.5-18.5$ & $52-58$ \\
\hline & $7(a)$ & $"$ & $"$ & $"$ & $3.8-4.2$ & $17.5-18.5$ & $51-57$ \\
\hline & $7(b)$ & $"$ & $"$ & $"$ & $3.8-4.2$ & $17.5-18.5$ & $54-58$ \\
\hline & $8(a)$ & 300 & 800 & $"$ & $3.7-4.0$ & $18.0-19.0$ & $54-62$ \\
\hline & $8(b)$ & " & " & $"$ & $3.7-4.0$ & $18.0-19.0$ & $54-62$ \\
\hline & 9 & " & " & $"$ & $3.6-4.0$ & $18.0-19.0$ & $57-61$ \\
\hline & 10 & 250 & 700 & $"$ & $3.7-4.3$ & $18.0-19.0$ & $53-60$ \\
\hline & 11 & 300 & 800 & 40 & $3.6-4.2$ & $18.0-19.0$ & $57-60^{a}$ \\
\hline & $12(a)$ & 280 & 750 & $"$ & $3.9-4.2$ & - & $52-60^{a}$ \\
\hline & $12(b)$ & $"$ & $"$ & $"$ & $\sim 3.8$ & $17.5-18.5$ & $52-56^{a}$ \\
\hline & 13 & 150 & 450 & $"$ & $3.9-4.2$ & $17.5-18.5$ & $48-56^{a}$ \\
\hline & $14(a)$ & " & " & 80 & $3.7-3.9$ & $17.5-18.5$ & $68-75^{a}$ \\
\hline & $14(b)$ & $"$ & $"$ & $"$ & $3.8-4.1$ & $17.0-18.5$ & $70-75^{a}$ \\
\hline Vee-doors & $15(a)$ & 150 & 450 & 80 & $3.8-4.2$ & $17.0-18.5$ & $68-77$ \\
\hline \multirow[t]{5}{*}{$\left(6.4 \mathrm{~m}^{2}\right)$} & $15(b)$ & $"$ & $"$ & $"$ & - & - & - \\
\hline & $16(a)$ & $"$ & $"$ & $"$ & $3.7-4.1$ & $17.0-18.5$ & - \\
\hline & $16(b)$ & " & $"$ & $"$ & $3.7-4.1$ & - & $68-73$ \\
\hline & 17 & $"$ & $"$ & 40 & $3.7-4.0$ & $17.0-18.0$ & - \\
\hline & 18 & 135 & $"$ & $"$ & $3.9-4.1$ & - & - \\
\hline
\end{tabular}

a Rigging of doors changed to minimize angle of attack. 
Waco-doors $\left(7.5 \mathrm{~m}^{2}\right)$. Observations were made during eight bottom tows with these doors. During the first five tows, the rigging of the doors was the same as that which is normally used on the survey vessel. The measurements of the vertical opening ranged from 3.5 to $3.9 \mathrm{~m}$ and the wing-spread from 19.0 to $20.5 \mathrm{~m}$. The door-spread was quite stable, with measurements varying from 63 to $68 \mathrm{~m}$ for the $40 \mathrm{~m}$ bridles and from 81 to $89 \mathrm{~m}$ for the $80 \mathrm{~m}$ bridles. From these figures, the bridle angles were calculated to be about 25 and 21 degrees respectively. However, the difference between these bridle angles had no apparent effect on headline height and wing-spread of the trawl. For the last three tows of the series, the rigging of the doors was changed to minimize the angle of their attack, but no effect on the gear parameters was recorded.

Waco-doors $\left(6.0 \mathrm{~m}^{2}\right)$. Observations were made during 14 tows with these doors (Table 1). During the first eight tows, the rigging was the same as that normally used on the survey vessel. At a depth of $150 \mathrm{~m}$, these doors resulted in higher vertical opening of the trawl (3.8-4.2 $\mathrm{m})$ and lower wing-spread (17.5-18.5 $\mathrm{m}$ ) and door-spread $(51-58 \mathrm{~m})$ than the $7.5 \mathrm{~m}^{2}$ doors. The bridle angle was about 20 degrees for the $40 \mathrm{~m}$ bridles. Tows at greater depths $(250-300 \mathrm{~m})$ indicated a slight increase in wing-spread and door-spread. For the remaining six tows of this series, the doors were rigged to minimize the angle of their attack, but no apparent effect on wing-spread and door-spread was recorded. With $80 \mathrm{~m}$ bridles (tows $14 \mathrm{a}$ and $14 \mathrm{~b}$ ), the bridle angle was reduced to about 18 degrees without any apparent effect on vertical opening or wingspread.

Vee-doors $\left(6.4 \mathrm{~m}^{2}\right)$. Observations were made during six tows with these doors (Table 1), which were rigged with minimum angle of attack, as normally used aboard the research vessel. Measurements of all three gear parameters were obtained during only one tow with these doors because of problems with the instruments. The available measurements were about the same as those for the $6.0 \mathrm{~m}^{2}$ Waco-doors.

\section{Acoustics and catch}

The tests were conducted in a rather small geographic area (Fig. 1). Most of the data were collected from depths between 100 and $200 \mathrm{~m}$ where the type of acoustic recordings and species composition, as well as the size composition of the cod and haddock, were relatively homogeneous. Cod and haddock were recorded from the bottom up to about $50 \mathrm{~m}$, but the largest concentrations were near the bottom. The cod were mainly in the length range of $35-55 \mathrm{~cm}$, while most of the haddock were $25-45 \mathrm{~cm}$. The acoustic results were mainly from the $100-200 \mathrm{~m}$ depth zone except when specifically noted as being from the 200-300 $\mathrm{m}$ zone. The recordings at these greater

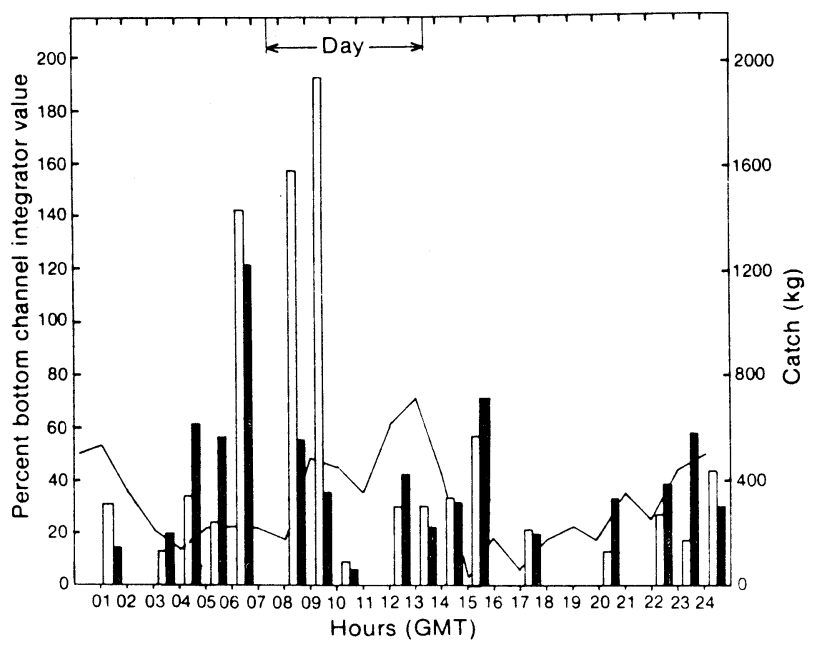

Fig. 3. Variation in mean percentage of total integrator values in the 4-m bottom channel with time of day, together with catches $(\mathrm{kg} / \mathrm{hr}$ ) of cod (open bars) and haddock (black bars), from the January 1985 survey

depths were generally closer to the bottom and the fish were somewhat larger.

Size and species composition of the fish in "pelagic" recordings above the headrope were assumed to be the same as those in the bottom trawl catches. According to Hylen et al. (MS 1985), this is a rough assumption, but limited variation in vertical distribution has a negligible effect on the analyses.

Day-night variations. The relative amount of the total integrator value in the bottom channel was assumed to reflect the vertical distribution of the fish. The mean percentages of the integrator values in the 4 $m$ bottom channel are given on a time axis (GMT) in Fig. 3, together with the cod and haddock catches. There was a slight tendency for fish recordings to be concentrated in the bottom channel during the day and also to some extent at midnight. The $10-\mathrm{m}$ bottom channel observations (not shown) were fewer and more difficult to interpret. There was great variation in catch size (Fig. 3), with the cod catches being largest just before dawn and early in the day and the haddock catches showing a less prominent maximum just before dawn. There was no significant correlation between the relative contribution of the integrator values from the bottom channel and catch sizes.

During the cruise, two short experimental surveys were conducted, one during the night (2207-0400 GMT) and the other during daylight (0730-1215 GMT). The cruise tracks were approximately the same and the depth of the area was mainly between 100 and $200 \mathrm{~m}$. The corresponding day and night integrator values were as follows: 


\begin{tabular}{lrrrrrrrrr}
\hline Day & 64 & 173 & 186 & 38 & 49 & 36 & 85 & 95 & 24 \\
Night & 3 & 41 & 24 & 61 & 27 & 31 & 14 & 25 & 38 \\
\hline
\end{tabular}

All of the day values except two were larger than the corresponding night values, and the mean day value was 2.8 times greater than the mean night value.

Consideration of all data for the cruise by depth zone for day and night recordings resulted in the following mean integrator values (numbers of observations in parentheses):

\begin{tabular}{ccc}
\hline Depth & Day & Night \\
\hline $100-200 \mathrm{~m}$ & $189(55)$ & $37(189)$ \\
$200-300 \mathrm{~m}$ & $34(14)$ & $28(31)$ \\
\hline
\end{tabular}

For the 100-200 m depth zone, the results were similar to those from the short surveys, with the mean day value being about five times higher than the corresponding night value. However, the day-night difference at 200-300 m was not noteworthy. A plot of the mean integrator values (with standard deviations) from the 100-200 m depth zone on a time scale (Fig. 4) clearly demonstrates an increase in the early morning and a decrease in the afternoon, but the standard deviations were quite large.

The plot of the pelagic integrator values against the total integrator values (4-m bottom channel) (Fig. 5 ) indicates a highly linear trend, for which the regression was calculated to be

$$
y=0.9 x-3.9 \quad(r=0.95)
$$

The data include both day and night values. The closeness of the points to the line of $y=x$ indicates that

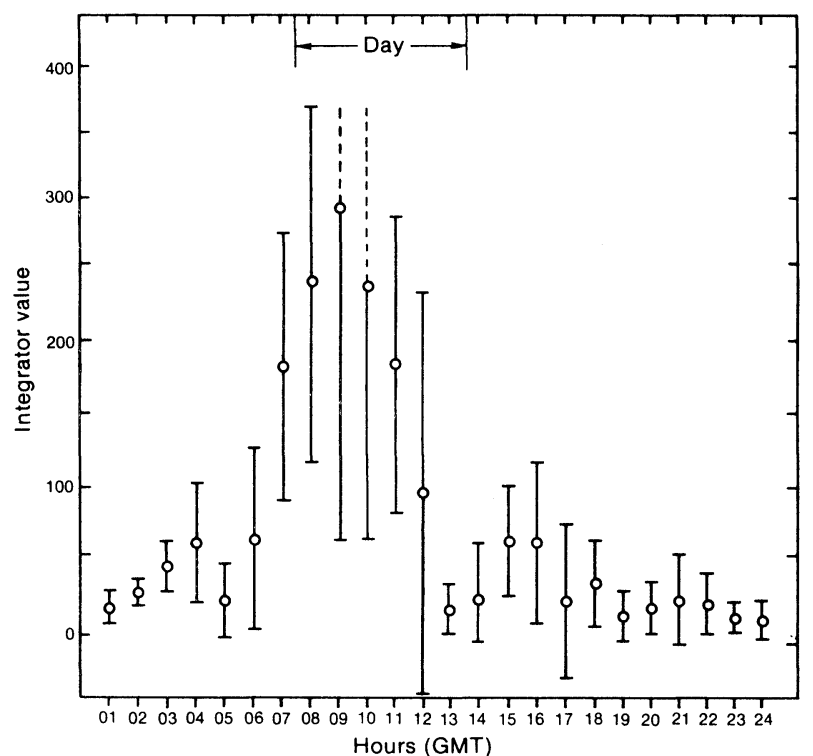

Fig. 4. Variation in mean integrator values and their standard deviations with time of day. pronounced vertical day-night migrations do not occur. A similar regression was calculated from the results for the $10 \mathrm{~m}$ bottom channel:

$$
y=0.7 x-1.8 \quad(r=0.96)
$$

Vertical distribution and fish density. The linear relationship between pelagic integrator values and total integrator values indicates that the amount of pelagically-distributed cod and haddock is dependent on the total density of these species. This impression is further illustrated in the plot of relative bottom channel integrator values against total integrator values (Fig. 6 ). The bottom-channel percentages decrease rapidly

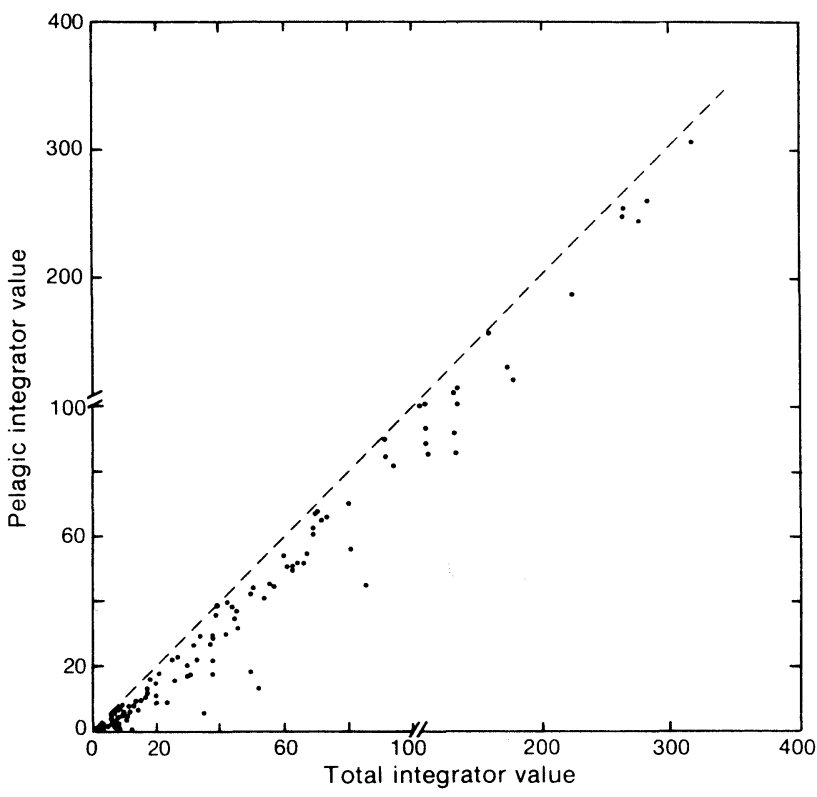

Fig. 5. Plot of pelagic integrator values against total integrator values from the $4-m$ bottom channel, relative to the $y=x$ line.

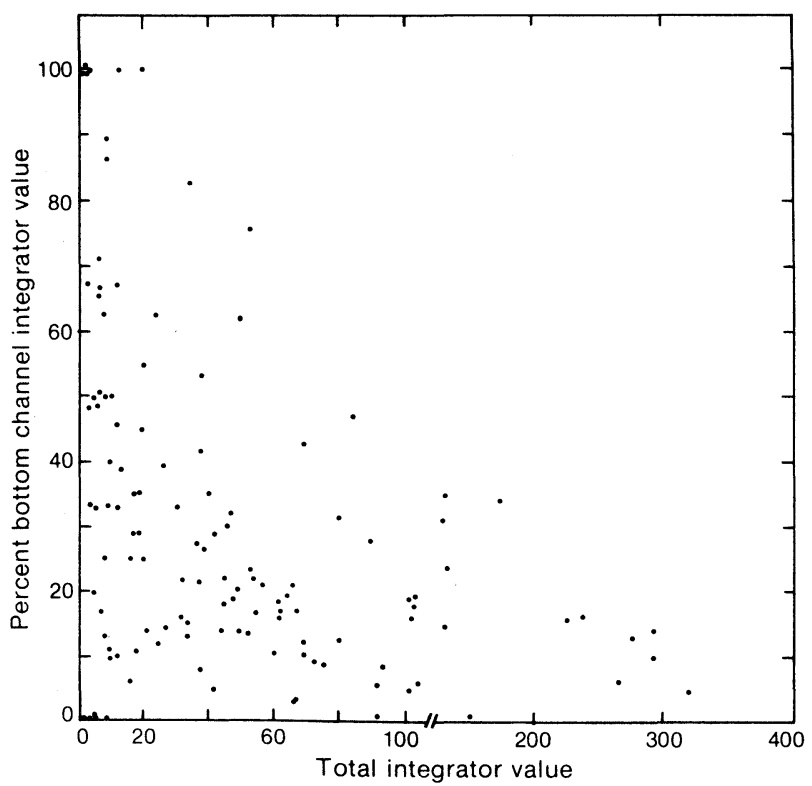

Fig. 6. Plot of percentages of total interator values in the $4 \mathrm{~m}$ bottom channel against total integrator values. 


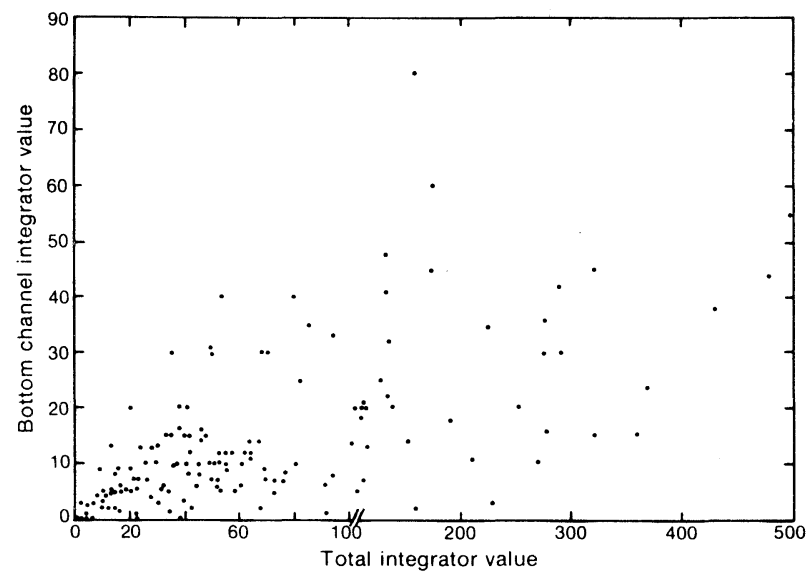

Fig. 7. Plot of interator values from the 4-m bottom channel against total integrator values.

with increasing total integrator values. There is only a slight tendency for the frequency of high integrator values in the bottom channel to increase with increasing total integrator values (Fig. 7).

\section{Discussion}

\section{Trawl dimensions}

The observations on trawl performance revealed several aspects of the geometry and performance of the gear that could have reduced its efficiency for sampling different species and size-groups of fish, and may explain some of the ship-to-ship differences which have been observed during routine surveys.

Vertical opening. This parameter varied from 3.5 to $4.2 \mathrm{~m}$ during the experiment (Table 1). These values are well below the operating height of $6 \mathrm{~m}$ which has been assumed in calculating abundance ard biomass from trawl surveys (Hylen and Nakken, MS 1983). The relatively low vertical opening may have reduced the efficiency of the trawl in situations where concentrations of fish extended several meters up into water column. Different vertical reactions of cod and haddock in the catch zone of the trawl may also affect the species composition of catches. Haddock have been observed to rise and enter the trawl at a higher level than cod, and they may possibly escape above the headline (Main and Sangster, 1981b).

Wing-spread. Measurements with the $7.5 \mathrm{~m}^{2}$ Waco-doors indicated a rather large spread (about 20 $\mathrm{m}$ ) for a trawl with a $29 \mathrm{~m}$ headrope, implying that the gear may have been overspread. In addition to the effect which different wing-spreads may have on catching efficiency, overspreading of the trawl may affect the bottom contact of the bobbins. Most of the towing strain on a well-tuned bottom trawl is taken by the headrope, with the groundrope being somewhat slack (Wathne, 1977) to allow the bobbins to make good contact with the bottom. However, when the trawl is grossly overspread, the groundrope is probably too taut to make good bottom contact along its entire length. This may provide avenues of escape below the bobbins for those species of fish, such as cod and flatfishes, which exhibit a downward escape reaction (Harden-Jones et al., 1977; Main and Sangster, 1981b; Korotkov, MS 1984).

Door-spread and bridle angle. The high doorspread/wing spread ratio with the $7.5 \mathrm{~m}^{2}$ Waco-doors and the $40 \mathrm{~m}$ bridle resulted in a very high bridle angle (about 25 degrees). At such high bridle angles, the herding efficiency of the bridles is reduced and this may result in a strong size-selection effect (Carrothers, 1981; Wardle, 1977, 1983). In addition, with such high bridle angles, it is most probably that the sand-clouds pass well outside the wings of the trawl, thus reducing the important herding effects of sand-clouds (Main and Sangster, 1981a, 1981b; Korotkov, MS 1984). The lower bridle angles with the two smaller doors, and especially with $80 \mathrm{~m}$ bridles, may result in higher sand clouds and better bridle-herding efficiency.

Identification of "bad" tows. During 5 of the 28 tows, the measurements indicated that the gear was not fully spread or was not on bottom for a substantial part of the tow. When the gear was not fully spread, post-tow examination showed scratches and mud deposits on the bracket and often on the top of one or both doors, indicating that the doors had collapsed and caused an unusually low spread (these measurements were not included in Table 1). The instrument also detected unsatisfactory contact of the trawl with the bottom. This occurred when echoes were received from the groundrope, which, for proper fishing, should have been well behind the headline and not giving an echo.

Trawl measurements from some tows during routine surveys (Engås and West, 1987) showed about the same relative frequency of "bad" tows as mentioned above. Without instruments, these tows would have been considered as "normal" tows and used in the estimation of abundance and biomass without adjustment.

\section{Acoustic and catch}

The acoustic recordings were made under rather favorable conditions, with the catches consisting mainly of cod, haddock and flatfishes. The problem of separating cod-haddock recordings from other fish traces was generally small, but, when present, the effect on results was assurned to be limited. The bottom channel was set to $4 \mathrm{~m}$, which was shown to be the maximum height of the trawl during the first tows. 
A prominent vertical day-night migration may influence the bottom trawl catches and hence the codhaddock estimates of abundance in the Barents Sea from both the acoustic and bottom trawl surveys. During this experimental cruise, no prominent vertical migration of species was observed. It must be stressed, however, that the duration of daylight and other environmental factors change very much during the year at these latitudes, and, consequently, fish behavior may vary seasonably.

The cod and haddock catches $(\mathrm{kg} / \mathrm{hr}$ ) tended to be maximum at dawn and in the early morning. This could not be linked to a corresponding increase in abundance on the bottom from acoustic data. Detection of fish close to the bottom (dead-zone) is a limitation of abundance estimation by acoustics (Johannesson and Mitson, 1983). A vertical migration in and out of the dead-zone could explain the lack of correlation between catch and acoustic abundance. However, such explanation is not possible here, because there was evidently no vertical migration of fish above the dead-zone (Fig. 3). The lack of correlation between catch and acoustic abundance may be due to considerable variation in catchability during day and night trawling, i.e. different behavior in relation to the gear. This may have an effect on the results from trawl surveys and should be investigated further.

The most prominent and surprising difference in day-night results was the great discrepancy between the day and night integrator values at $100-200 \mathrm{~m}$ (Fig. 4). Day values were also much higher than night values during the short surveys in 100-200 m, the two exceptions being in an area where the depth approached 300 $\mathrm{m}$. As the phenomenon was observed in the shallow depth zone only, an explanation may be that fish in such depths have a ship avoidance reaction during the night (possibly influenced by light from the ship), whereby their target strength is reduced. Soundinduced ship avoidance effects were reported by Olsen et al. (1983). A considerable portion of the acoustic data was obtained while the ship was trawling at slow speed. However, the ship's influence on fish may be less at cruising speed. The day-night effect on acoustic estimates of cod and haddock abundance in shallow water is obvious, and the problem should be investigated further.

The integrator output results clearly show that the vertical distribution of cod and haddock is dependent on the total density of the two species. The linear regression (Fig. 5) is greatly dependent on the higher integrator values and indicates that about $90 \%$ of the integrator values were pelagic. A better indication of the vertical distribution at the lower fish densities is shown in Fig. 6, where up to $100 \%$ of the fish are found in the bottom channel. The bottom channel integrator values tend to increase towards a limit with increasing total values (Fig. 7). In conclusion, when densities of cod and haddock are low, they will be mainly concentrated close to the bottom and greater proportions of the stocks will be available to the bottom trawl than under high densities. Consequently, the abundance indices from bottom-trawl surveys at high fish densities will probably be too low relative to the estimates at low fish densities.

\section{References}

BLINDHEIM, J., P. K. EIDE, H. P. KNUDSEN, and G. VESTNES. 1982. A shipborne data logging and processing system for acoustic fish surveys. Fish. Res., 1: 142153.

CARROTHERS, P. J. G. 1981. Catch variability due to variations in groundfish otter trawl behavior and possibilities to reduce it through instrumented fishing gear studies and improved fishing procedures. Can. Spec. Publ. Fish. Aquat. Sci., 58: 247-257.

DALEN, J., and O. NAKKEN. MS 1983. On the application of the echo-integration method. ICES C.M. Doc., No. B:19, $30 \mathrm{p}$.

ENGÅS, A., and C. V. WEST. 1987. Observations of trawl performance during the Barents Sea cod and haddock surveys: potential sources of gear-related sampling bias. Fish. Res., 5: (in press).

HARDEN-JONES, F. R., A. R. MARGETTS, M. G. WALKER, and G. P. ARNOLD. 1977. The efficiency of the Granton trawl determined by sector-scanning sonar and acoustic transponding tags. ICES Rapp. Proc.-Verb., 170: 45-51.

HYLEN, A., and O. NAKKEN. MS 1983. Stock size of Northeast Arctic cod: estimates from survey data 1982/1983. ICES C.M. Doc., No. G:57, 13 p.

HYLEN, A, T. JAKOBSEN, O. NAKKEN, and K. SUNNANÅ. MS 1985. Preliminary report of the Norwegian investigations on young cod and haddock in the Barents Sea during the winter 1985. ICES C.M. Doc., No. G:68, 28 p.

1987. The use of acoustic and bottom trawl surveys in the assessment of North-East Arctic cod and haddock stocks. Proceedings of a workshop on comparative biology, assessment, and management of gadoids from the North Pacific and Atlantic oceans, Seattle, Washington, 24-28 June 1985: (in press).

JOHANNESSON, K. A., and R. B. MITSON. 1983. Fisheries acoustics: a practical manual for aquatic biomass estimation. FAO Fish. Tech. Pap., 240: 1-249.

KOROTKOV, V. K. MS 1984. Fish behavior in a catching zone and influence of bottom trawl rig elements on selectivity. ICES C.M. Doc., No. B:15, 14 p.

MAIN, J., and G. I. SANGSTER. 1981a. A study of sand clouds produced by trawl boards and their possible effect on fish capture. Scot. Fish. Res. Rep., 20: 1-20.

1981b. A study of fish capture process in a bottom trawl by direct observations from a towed underwater vehicle. Scot. Fish. Res. Rep., 23: 1-23.

OLSEN, K., J. ANGELL, F. PETTERSEN, and A. LOVIK. 1983. Observed fish reactions to a surveying vessel with special reference to herring, cod, capelin and polar cod. FAO Fish. Rep., 300: 131-138. 
WARDLE, C. S. 1977. Effects of size on the swimming speeds of fish. In Scale effects in animal locomotion (p. 299-313), T. J. Pedley (ed.), Academic Press, London and New York, 545 p.

1983. Fish reaction to towed fishing gears. In Experi- mental biology at sea (p. 167-195), A. MacDonald and I. G. Priede (ed.), Academic Press, London and New York, $414 \mathrm{p}$.

WATHNE, F. 1977. Performance of trawls used in resource assessment. Mar. Fish. Rev., 39(6): 16-23. 